Journal of Research in Nursing

Vol. 3, No. 1, 2017

Print ISSN 2244-2723

University of Cebu

Cebu City, Cebu, Philippines

\title{
Dengue Control Measures in Tagbilaran City, Bohol, Philippines
}

\author{
Edgar E. Acosta \\ Mauro Allan P. Amparado
}

\section{Abstract}

The study determined the implementation of the Department of Health's Dengue control measures in Tagbilaran City, Bohol, Philippines. It specifically sought to answer the following questions: profile of the respondents in terms of age, highest educational attainment, family income, and number of children 12 years old and below; level of implementation of Dengue Control Program in terms of search and destroy, and self-protection measures; and perceptions on Dengue control measures in terms of seeking early consultation and fogging.

This study utilized the descriptive-correlational design. There were 398 respondents who were involved in this study. They were mothers, 18 years old and above and from the 15 barangays of Tagbilaran City, Bohol. A modified researcher-made questionnaire was used to collect data. This study is a replication of the study of Rufo \& Amparado (2017) on Dengue control measures conducted in the City of Naga, Cebu, Philippines.

The results revealed that majority of the respondents belonged to the age range of 26 to 45 years old, college students, has an income range of 5,000 to 10,000 Philippine pesos per 
month and have two children below 12 years old. In terms of search and destroy, and self-protection measures, mothers have strong implementation on covering water containers with tight lid as well as storing properly and discarding non-essential containers like bottles, cans, jars and tires. Moderate implementation was on changing flowers from water vases, and cleaning the vicinity from drains and garbage. Mothers have poor implementation measures on the use of mosquito repellants, mosquito nets at daytime, and the use of household insecticide aerosol, insecticide vaporizers, or mosquito coils. Most of them recognized the early signs and symptoms of dengue such as severe headache and fever. Nearly all mothers brought their child to the nearest health facility as part of their initial management every time their child experiences fever. Most of them do not agree on the use of fogging measures to be done against dengue control. There were significant relationships between the profile and: search and destroy measures; selfprotection measures; and knowledge on the early signs and symptoms of dengue.

In conclusion, dengue prevention and control in the community have not been fully implemented because of the lack of community-based, integrated health control program which are sustainable and health-enhancing. Recommendations include replicating the study and the implementation of the proposed action plan.

Recommended citation: Acosta, E. E. \& Amparado, M. A. P. (2017). Dengue Control Measures in Tagbilaran City, Bohol, Philippines. Journal of Research in Nursing, 3(1), 20-29.

Reference: Rufo, F. J. M. \& Amparado, M. A. P. (2017). Implementation of Dengue Control Measures in City of Naga, Cebu, Philippines. IAMURE International Journal of Social Sciences, 19(1), 58-76. 